\title{
MATRIX TRANSFORMATIONS BETWEEN THE SPACES OF CESÀRO SEQUENCES AND INVARIANT MEANS
}

\author{
M. MURSALEEN, E. SAVAŞ, M. AIYUB, AND S. A. MOHIUDDINE \\ Received 6 March 2005; Revised 16 October 2005; Accepted 18 December 2005
}

The main purpose of this paper is to characterize the classes of matrices $\left(\operatorname{ces}[(p),(q)], c^{\sigma}\right)$ and $\left(\operatorname{ces}[(p),(q)], l_{\infty}^{\sigma}\right)$, where $c^{\sigma}$ is the space of all bounded sequences all of whose $\sigma$ means are equal, $l_{\infty}^{\sigma}$ is the space of $\sigma$ - bounded sequences, and ces $[(p),(q)]$ is the generalized Cesàro sequence space.

Copyright (c) 2006 Hindawi Publishing Corporation. All rights reserved.

\section{Introduction}

Let $\omega$ be the space of all sequences, real or complex, and let $l_{\infty}$ and $c$, respectively, be the Banach spaces of bounded and convergent sequences $x=\left(x_{n}\right)$ with norm $\|x\|=$ $\sup _{k \geq 0}\left|x_{k}\right|$. Let $\sigma$ be a mapping of the set of positive integers into itself. A continuous linear functional $\phi$ on $l_{\infty}$ is said to be an invariant mean or a $\sigma$-mean if and only if (i) $\phi(x) \geq 0$, when the sequence $x=\left(x_{n}\right)$ has $x_{n} \geq 0$ for each $\mathrm{n}$; (ii) $\phi(e)=1$, where $e=(1,1,1, \ldots)$; and (iii) $\phi\left(\left(x_{\sigma(n)}\right)\right)=\phi(x), x \in l_{\infty}$.

For certain kinds of mappings, every $\sigma$ - mean extends the limit functional $\phi$ on $c$ in the sense that $\phi(x)=\lim x$ for $x \in c$ (see $[2,15]$ ). Consequently, $c \subset c^{\sigma}$, where $c^{\sigma}$ is the set of bounded sequences, all of whose invariant means are equal (see $[1,9,10])$. When $\sigma$ is translation, the $\sigma$ - means are classical Banach limits on $l_{\infty}$ (see [2]) and $c^{\sigma}$ is the set of almost convergent sequences $\hat{c}$ (see [7]). Almost convergence for double sequences was introduced and studied by Móricz and Rhoades [8] and further by Mursaleen and Savaş [13], Mursaleen and Edely [12], and Mursaleen [11].

If $x=\left(x_{n}\right)$, write $T x=\left(T x_{n}\right)=\left(x_{\sigma(n)}\right)$, then

$$
c^{\sigma}=\left\{x \in l_{\infty}: \lim _{m \rightarrow \infty} t_{m, n}(x)=L, \text { uniformly in } n, L=\sigma-\lim x\right\},
$$

where

$$
t_{m, n}(x)=\frac{1}{m+1} \sum_{j=0}^{m} T^{j} x_{n} \text { with } T^{j} x_{n}=x_{\sigma^{j}(n)}, t_{-1, n}(x)=0 .
$$

We define $l_{\infty}^{\sigma}$ the space of $\sigma$ - bounded sequences (Ahmad et al. [2]) in the following way.

Hindawi Publishing Corporation

International Journal of Mathematics and Mathematical Sciences

Volume 2006, Article ID 74319, Pages 1-8

DOI 10.1155/IJMMS/2006/74319 
Let $x_{n}=z_{0}+z_{1}+z_{2}+\cdots+z_{n}$ and

$$
l_{\infty}^{\sigma}=\left\{z \in \omega: \sup _{m, n}\left|\psi_{m, n}(z)\right|<\infty\right\}
$$

where

$$
\begin{aligned}
\psi_{m, n}(z) & =t_{m, n}(x)-t_{m-1, n}(x) \\
& =\frac{1}{m(m+1)} \sum_{j=1}^{m} j \sum_{i=h_{j-1}+1}^{h_{j}} z_{i}, \quad h_{j}=\sigma^{j}(n) .
\end{aligned}
$$

If $\sigma(n)=(n+1)$, then $l_{\infty}^{\sigma}$ is the set of almost bounded sequences $\widehat{l_{\infty}}$ (see [14]).

Let $A=\left(a_{n k}\right)$ be an infinite matrix of complex numbers $a_{n k}(n, k=1,2, \ldots)$ and $X, Y$ two subsets of $\omega$. We say that the matrix $A$ defines a matrix transformation from $X$ into $Y$ if for every sequence $x=\left(x_{k}\right) \in X$ the sequence $A(x)=\left(A_{n}(x)\right) \in Y$, where $A_{n}(x)=$ $\sum_{k} a_{n k} x_{k}$ converges for each $n$. We denote the class of matrix transformations from $X$ into $Y$ by $(X, Y)$.

The main purpose of this paper is to characterize the classes $\left(\operatorname{ces}[(p),(q)], c^{\sigma}\right)$ and $\left(\operatorname{ces}[(p),(q)], l_{\infty}^{\sigma}\right)$ and deduce some known and unknown interesting results as corollaries.

The classes $\left(\operatorname{ces}[(p),(q)], c^{\sigma}\right)$ and $\left(\operatorname{ces}[(p),(q)], l_{\infty}^{\sigma}\right)$ are due to Khan and Rahman [4].

If $\left\{q_{n}\right\}$ is a sequence of positive real numbers, then for $p=\left(p_{r}\right)$ with inf $p_{r}>0$, we define the space ces $[(p),(q)]$ by

$$
\operatorname{ces}[(p),(q)]=\left\{x \in \omega: \sum_{r=0}^{\infty}\left(\frac{1}{Q_{2^{r}}} \sum_{r} q_{k}\left|x_{k}\right|\right)^{p_{r}}<\infty\right\}
$$

where $Q_{2^{r}}=q_{2^{r}}+q_{2^{r+1}}+\cdots+q_{2^{r+1}-1}$ and $\sum_{r}$ denotes a sum over the range $2^{r} \leq k<2^{r+1}$. Remark 1.1. If $q_{n}=1$ for all $n$, then ces [( $\left.\left.p\right),(q)\right]$ reduces to ces $(p)$ studied by Lim [6]. Also, if $p_{n}=p$ for all $n$ and $q_{n}=1$ for all $n$, then ces $[(p),(q)]$ reduces to ces $p$ studied by Lim [5].

For any bounded sequence $p$, the space $\operatorname{ces}[(p),(q)]$ is a paranormed space with the paranorm given by (see [4])

$$
g(x)=\left(\sum_{r=0}^{\infty}\left(\frac{1}{Q_{2^{r}}} \sum_{r} q_{k}\left|x_{k}\right|\right)^{p_{r}}\right)^{1 / M}
$$

if $H=\sup _{r} p_{r}<\infty$ and $M=\max (1, H)$. 


\section{Sequence-to-sequence transformations}

In this section, we characterize the classes $\left(\operatorname{ces}[(p),(q)], c^{\sigma}\right)$ and $\left(\operatorname{ces}[(p),(q)], l_{\infty}^{\sigma}\right)$.

We write $a(n, k)$ to denote the elements $a_{n k}$ of the matrix $A$, and for all integers $n, m \geq$ 1 , we write

$$
\begin{aligned}
t_{m n}(A x) & =\frac{A x_{n}+T A x_{n}+\cdots+T^{m} A x_{n}}{m+1} \\
& =\sum_{k} t(n, k, m) x_{k},
\end{aligned}
$$

where $t(n, k, m)=1 /(m+1) \sum_{j=0}^{m} a\left(\sigma^{j}(n), k\right)$.

We also define the spaces of $\sigma$-convergent series and $\sigma$-bounded series, respectively, as follows:

$$
\begin{gathered}
c_{s}^{\sigma}=\left\{x: \sum_{i=1}^{m}\left(\frac{1}{i+1} \sum_{j=0}^{i} x_{\sigma^{j}(n)}\right) \text { is convergent uniformly in } n \text {, as } m \longrightarrow \infty\right\}, \\
b_{s}^{\sigma}=\left\{x: \sup _{n, m} \sum_{i=1}^{m}\left(\frac{1}{i+1} \sum_{j=0}^{i} x_{\sigma^{j}(n)}\right)<\infty\right\} .
\end{gathered}
$$

If we take $\sigma(n)=n+1, c_{s}^{\sigma}$ and $b_{s}^{\sigma}$ reduce to $\widehat{c}_{s}$ and $\hat{b}_{s}$, as defined below:

$$
\begin{gathered}
\hat{\mathcal{c}}_{s}=\left\{x: \sum_{i=1}^{m}\left(\frac{1}{i+1} \sum_{j=0}^{i} x_{j+n}\right) \text { is convergent uniformly in } n \text {, as } m \rightarrow \infty\right\}, \\
\hat{b}_{s}=\left\{x: \sup _{n, m} \sum_{i=1}^{m}\left(\frac{1}{i+1} \sum_{j=0}^{i} x_{j+n}\right)<\infty\right\} .
\end{gathered}
$$

Now we prove the following theorem.

Theorem 2.1. Let $1<p_{r} \leq \sup _{r} p_{r}<\infty$. Then $A \in\left(\operatorname{ces}[(p),(q)], c^{\sigma}\right)$ if and only if

(i) there exists an integer $E>1$ such that for all $n$,

$$
U(E)=\sup _{m} \sum_{r=0}^{\infty}\left(Q_{2^{r}} \max _{r}\left(\frac{|t(n, k, m)|}{q_{k}}\right)\right)^{t_{r}} E^{-t_{r}}<\infty,
$$

where $1 / p_{r}+1 / t_{r}=1, r=0,1,2, \ldots$, and $\max _{r}$ means maximum over $2^{r} \leq k<2^{r+1}$; (ii) $a_{(k)}=\left(a_{n k}\right)_{n=1}^{\infty} \in c^{\sigma}$ for each $k$, that is, $\lim _{m} t(n, k, m)=u_{k}$ uniformly in $n$, for each $k$.

In this case, $\sigma$-limit of $A x$ is $\sum_{k=1}^{\infty} u_{k} x_{k}$.

Proof

Neccessity. Suppose that $A \in\left(\operatorname{ces}[(p),(q)], c^{\sigma}\right)$. Now $\sum_{k=1}^{\infty} t(n, k, m) x_{k}$ exists for each $m$ and $n$ and $x \in \operatorname{ces}[(p),(q)]$, whence $\{t(n, k, m)\}_{k} \in \operatorname{ces}^{*}[(p),(q)]$ for each $m$ and $n$, (see F. M. Khan and M. A. Khan [3] for Köthe-Toeplitz and continuous duals of ces $[(p),(q)])$. 
4 Matrix transformations

Therefore, it follows that each $\left\{f_{m, n}\right\}_{m}$ defined by

$$
f_{m, n}(x)=t_{m, n}(A x)
$$

is an element of ces*[(p), $(q)]$. Since ces $[(p),(q)]$ is complete and further for each $n$, $\sup _{m}\left|t_{m, n}(A x)\right|<\infty$ on ces[( $\left.\left.p\right),(q)\right]$. Now arguing with the uniform boundedness principle, we have condition (i). Since $e_{k} \in \operatorname{ces}[(p),(q)]$, condition (ii) follows.

Sufficiency. Suppose that the conditions hold. Fix $n \in \mathbb{N}$. For every integer $s \geq 1$, from (i) we have

$$
\sum_{r=0}^{s}\left(Q_{2^{r}} \max _{r}\left(q_{k}^{-1}|t(n, k, m)|\right)\right)^{t_{r}} E^{-t_{r}} \leq \sup _{m} \sum_{r=0}^{\infty}\left(Q_{2^{r}} \max _{r}\left(q_{k}^{-1}|t(n, k, m)|\right)\right)^{t_{r}} E^{-t_{r}} .
$$

Now letting $s \rightarrow \infty$, we obtain

$$
\lim _{m \rightarrow \infty} \sum_{r=0}^{\infty}\left(Q_{2^{r}} \max _{r}\left(q_{k}^{-1}|t(n, k, m)|\right)\right)^{t_{r}} E^{-t_{r}} \leq \sup _{m} \sum_{r=0}^{\infty}\left(Q_{2^{r}} \max _{r}\left(q_{k}^{-1}|t(n, k, m)|\right)\right)^{t_{r}} E^{-t_{r}} .
$$

Therefore, from (ii) we have

$$
\sum_{r=0}^{\infty}\left(Q_{2^{r}} \max _{r}\left(q_{k}^{-1}\left|u_{k}\right|\right)\right)^{t_{r}} E^{-t_{r}} \leq \sup _{m} \sum_{r=0}^{\infty}\left(Q_{2^{r}} \max _{r}\left(q_{k}^{-1}|t(n, k, m)|\right)\right)^{t_{r}} E^{-t_{r}}<\infty .
$$

Hence $\left(u_{k}\right)_{k}$ and $\{t(n, k, m)\}_{k} \in$ ces $^{*}[(p),(q)]$, therefore the series $\sum_{k=1}^{\infty} t(n, k, m) x_{k}$ and $\sum_{k=1}^{\infty} u_{k} x_{k}$ converge for each $m$ and $n$ and $x \in \operatorname{ces}[(p),(q)]$. For given $\epsilon>0$ and $x \in$ $\operatorname{ces}[(p),(q)]$, choose $s$ such that

$$
\left(\sum_{r=s+1}^{\infty}\left(\frac{1}{Q_{2^{r}}} \sum_{r} q_{k}\left|x_{k}\right|\right)^{p_{r}}\right)^{1 / M}<\epsilon
$$

Since (ii) holds, there exists $m_{0}$ such that

$$
\left|\sum_{k=1}^{s} t(n, k, m)-u_{k}\right|<\epsilon \quad \forall m>m_{0}
$$

Since (i) holds, it follows that

$$
\left|\sum_{k=s+1}^{\infty} t(n, k, m)-u_{k}\right| \text { is arbitrary small. }
$$


Therefore,

$$
\lim _{m} \sum_{k=1}^{\infty} t(n, k, m) x_{k}=\sum_{k=1}^{\infty} u_{k} x_{k}, \quad \text { uniformly in } n .
$$

This completes the proof.

Remark 2.1. For different choices of $p, q$, and $\sigma$, we can deduce many corollaries from the above theorem to characterize the matrix classes, for example, $\left(\operatorname{ces}(p), c^{\sigma}\right),\left(\operatorname{ces}_{p}, c^{\sigma}\right)$, $\left(\operatorname{ces}_{p}(q), c^{\sigma}\right),(\operatorname{ces}[(p),(q)], \hat{c})$, and so forth. The class $(\operatorname{ces}(p), \hat{c})$ was characterized by $\mathrm{F}$. M. Khan and M. A. Khan [3] which we can obtain directly from our theorem by taking $q_{n}=1$ for all $n$ and $\sigma(n)=n+1$.

We write (see [2])

$$
\begin{gathered}
x_{0}=z_{0}+z_{1}+\cdots+z_{n}, \\
\psi_{m, n}(A z)=\sum_{k} \alpha(n, k, m) z_{k},
\end{gathered}
$$

where

$$
\alpha(n, k, m)=\frac{1}{m(m+1)} \sum_{j=1}^{m} j\left[\sum_{i=h_{j-1}+1}^{h_{j}} a_{i k}\right], \quad h_{j}=\sigma^{j}(n) .
$$

Now we prove the following theorem.

Theorem 2.2. Let $1<p_{r} \leq \sup _{r} p_{r}<\infty$. Then $A \in\left(\operatorname{ces}[(p),(q)], l_{\infty}^{\sigma}\right)$ if and only if

$$
\sup _{m, n} \sum_{r=0}^{\infty}\left(Q_{2^{r}} \max _{r}\left(q_{k}^{-1}|\alpha(n, k, m)|\right)\right)^{t_{r}} E^{-t_{r}}<\infty
$$

where $E$ is an integer greater than 1 and $1 / p_{r}+1 / t_{r}=1, r=0,1,2, \ldots$

Proof

Necessity. Suppose that $A \in\left(\operatorname{ces}[(p),(q)], l_{\infty}^{\sigma}\right)$. Now $\sum_{k=1}^{\infty} \alpha(n, k, m) z_{k}$ exists for each $m$ and $n$ and $z \in \operatorname{ces}[(p),(q)]$, whence $\{\alpha(n, k, m)\}_{k} \in \operatorname{ces}^{*}[(p),(q)]$ for each $m$ and $n$. Therefore, it follows that $\left\{f_{m, n}\right\}$ defined by

$$
f_{m, n}(x)=\psi_{m, n}(A z)
$$

is an element of ces* $[(p),(q)]$. Since ces $[(p),(q)]$ is complete and further $\sup _{m, n}\left|\psi_{m, n}(A z)\right|$ $<\infty$ on ces $[(p),(q)]$, so by arguing with uniform boundedness principle, we have the condition. 
Sufficiency. Suppose that condition (2.15) holds. Fix $n \in \mathbb{N}$. For every integer $s \geq 1$ we have

$$
\sum_{r=0}^{s}\left(Q_{2^{r}} \max _{r}\left(q_{k}^{-1}|\alpha(n, k, m)|\right)\right)^{t_{r}} E^{-t_{r}} \leq \sup _{m, n} \sum_{r=0}^{\infty}\left(Q_{2^{r}} \max _{r}\left(q_{k}^{-1}|\alpha(n, k, m)|\right)\right)^{t_{r}} E^{-t_{r}} .
$$

So

$$
\begin{aligned}
\lim _{s \rightarrow \infty} \sum_{r=0}^{s}\left(Q_{2^{r}} \max _{r}\left(q_{k}^{-1}|\alpha(n, k, m)|\right)\right)^{t_{r}} E^{-t_{r}} \\
\quad \leq \sup _{m, n} \sum_{r=0}^{\infty}\left(Q_{2^{r}} \max _{r}\left(q_{k}^{-1}|\alpha(n, k, m)|\right)\right)^{t_{r}} E^{-t_{r}}<\infty .
\end{aligned}
$$

Hence $\{\alpha(n, k, m)\} \in$ ces $^{*}[(p),(q)]$. Therefore, the series $\sum_{k=1}^{\infty} \alpha(n, k, m) z_{k}$ converges for each $m$ and $n$ and $z \in \operatorname{ces}[(p),(q)]$.

This completes the proof.

Remark 2.2. The matrix class $\left(\operatorname{ces}(p), \widehat{l_{\infty}}\right)$, was characterized by F. M. Khan and M. A. Khan [3] which we can obtain directly from the above theorem by letting $q_{n}=1$ for all $n$ and $\sigma(n)=n+1$. Besides, we can further deduce many corollaries for different choices of $p, q$, and $\sigma$.

\section{Sequence-to-series transformations}

For all integers $m, n \geq 1$, we write

$$
t_{m n}^{*}(A x)=\sum_{i=1}^{m} t_{i n}(A x)=\sum_{k} \sum_{i=1}^{m} \frac{1}{i+1} \sum_{j=0}^{i} a\left(\sigma^{j}(n), k\right) x_{k}=\sum_{k} t^{*}(m, n, k) x_{k}
$$

where

$$
t^{*}(m, n, k)=\sum_{i=1}^{m} \frac{1}{i+1} \sum_{j=0}^{i} a\left(\sigma^{j}(n), k\right)
$$

Theorem 3.1. Let $1<p_{r} \leq \sup _{r} p_{r}<\infty$. Then $A \in\left(\operatorname{ces}[(p),(q)], c_{s}^{\sigma}\right)$ if and only if

(i) there exists an integer $E>1$ such that for all $n$,

$$
U(E)=\sup _{m} \sum_{r=0}^{\infty}\left(Q_{2^{r}} \max _{r}\left(\frac{\left|t^{*}(n, k, m)\right|}{q_{k}}\right)\right)^{t_{r}} E^{-t_{r}}<\infty
$$

where $1 / p_{r}+1 / t_{r}=1, r=0,1,2, \ldots$, and $\max _{r}$ means maximum over $2^{r} \leq k \leq 2^{r+1}$; 
(ii) $a_{(k)}=\left\{a_{n k}\right\}_{n=1}^{\infty} \in c_{s}^{\sigma}$ for each $k$, that is, $\lim _{m} t^{*}(n, k, m)=u_{k}$ uniformly in $n$, for each $k$.

In this case, the $\sigma$-limit of $A x$ is $\sum_{k=1}^{\infty} u_{k} x_{k}$.

Theorem 3.2. Let $1<p_{r} \leq \sup _{r} p_{r}<\infty$. Then $A \in\left(\operatorname{ces}[(p),(q)], b_{\infty}^{\sigma}\right)$ if and only if

$$
\sup _{m, n} \sum_{r=0}^{\infty}\left(Q_{2^{r}} \max _{r}\left(q_{k}^{-1}\left|t^{*}(n, k, m)\right|\right)\right)^{t_{r}} E^{-t_{r}}<\infty,
$$

where $E$ is an integer greater than 1 and $1 / p_{r}+1 / t_{r}=1, r=0,1,2, \ldots$

Proofs of Theorems 3.1 and 3.2 are similar to those of Theorems 2.1 and 2.2, respectively.

Remark 3.1. If $\sigma$ is translation, then Theorems 3.1 and 3.2 give the characterization for the classes $\left(\operatorname{ces}[(p),(q)], \hat{c}_{s}\right)$ and $\left(\operatorname{ces}[(p),(q)], \hat{b}_{s}\right)$. As Remarks 2.1 and 2.2, for different choices of $p, q$, and $\sigma$, we can deduce many corollaries.

\section{References}

[1] Z. U. Ahmad and M. Mursaleen, An application of Banach limits, Proceedings of the American Mathematical Society 103 (1988), no. 1, 244-246.

[2] Z. U. Ahmad, M. Mursaleen, and Q. A. Khan, Invariant means and some matrix transformations, Southeast Asian Bulletin of Mathematics 23 (1999), no. 4, 533-539.

[3] F. M. Khan and M. A. Khan, Matrix transformation on certain sequence spaces, Tamkang Journal of Mathematics 19 (1988), no. 4, 25-30.

[4] F. M. Khan and M. F. Rahman, Infinite matrices and Cesàro sequence spaces, Analysis Mathematica 23 (1997), no. 1, 3-11.

[5] K. P. Lim, Matrix transformation in the Cesàro sequence spaces, Kyungpook Mathematical Journal 14 (1994), no. 2, 221-227.

[6] Matrix transformation on certain sequence spaces, Tamkang Journal of Mathematics 8 (1997), no. 2, 213-220.

[7] G. G. Lorentz, A contribution to the theory of divergent sequences, Acta Mathematica 80 (1948), $167-190$.

[8] F. Móricz and B. E. Rhoades, Almost convergence of double sequences and strong regularity of summability matrices, Mathematical Proceedings of the Cambridge Philosophical Society 104 (1988), no. 2, 283-294.

[9] M. Mursaleen, Matrix transformations between some new sequence spaces, Houston Journal of Mathematics 9 (1983), no. 4, 505-509.

[10] _ On some new invariant matrix methods of summability, The Quarterly Journal of Mathematics. Oxford. Second Series 34 (1983), no. 133, 77-86.

[11] Almost strongly regular matrices and a core theorem for double sequences, Journal of Mathematical Analysis and Applications 293 (2004), no. 2, 523-531.

[12] M. Mursaleen and O. H. H. Edely, Almost convergence and a core theorem for double sequences, Journal of Mathematical Analysis and Applications 293 (2004), no. 2, 532-540.

[13] M. Mursaleen and E. Savaş, Almost regular matrices for double sequences, Studia Scientiarum Mathematicarum Hungarica 40 (2003), no. 1-2, 205-212.

[14] S. Nanda, Some sequence spaces and almost boundedness, Matematički Vesnik 13(28) (1976), no. $2,179-186$. 


\section{Matrix transformations}

[15] R. A. Raimi, Invariant means and invariant matrix methods of summability, Duke Mathematical Journal 30 (1963), no. 1, 81-94.

M. Mursaleen: Department of Mathematics, Faculty of Science, King Abdul-Aziz University, P.O. Box 80203, Jeddah, The Kingdom of Saudi Arabia

E-mail address: mursaleen@math.com

E. Savaş: Department of Mathematics, Y. Y. University, 65080 Van, Turkey

E-mail address: ekremsavas@yahoo.com

M. Aiyub: Department of Mathematics, Aligarh Muslim University (AMU),

Aligarh 202002, India

E-mail address: mohdaiyub@rediffmail.com

S. A. Mohiuddine: Department of Mathematics, Aligarh Muslim University (AMU), Aligarh 202002, India

E-mail address: mohiuddine@math.com 


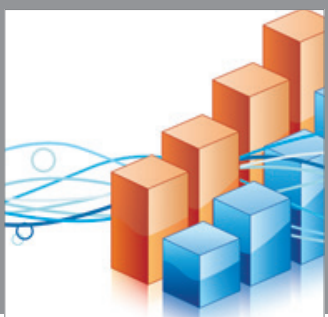

Advances in

Operations Research

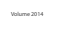

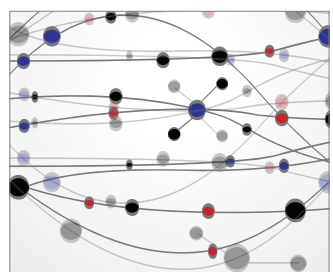

\section{The Scientific} World Journal
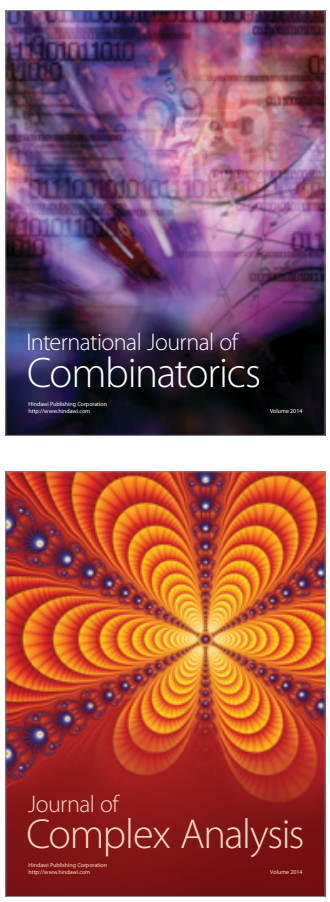

International Journal of

Mathematics and

Mathematical

Sciences
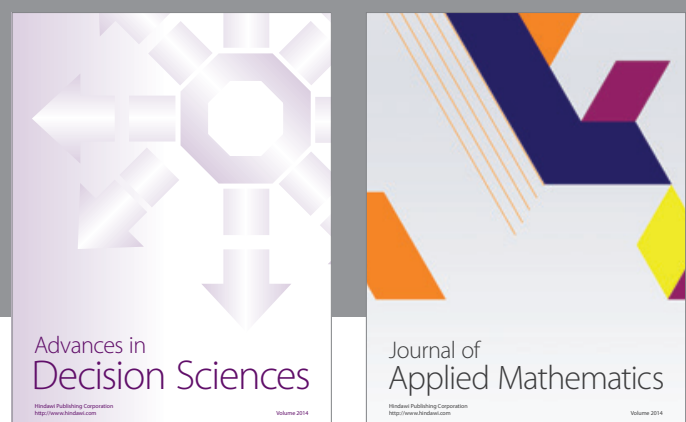

Journal of

Applied Mathematics
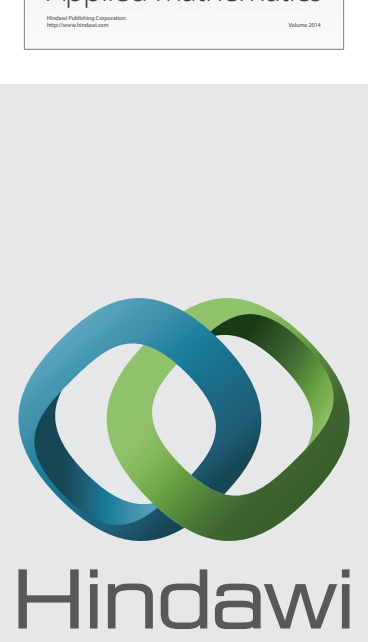

Submit your manuscripts at http://www.hindawi.com
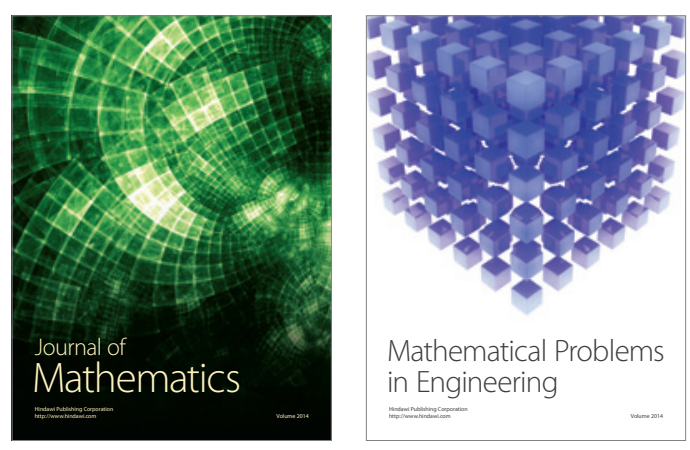

Mathematical Problems in Engineering
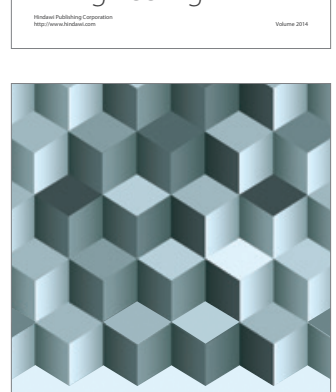

Journal of

Function Spaces
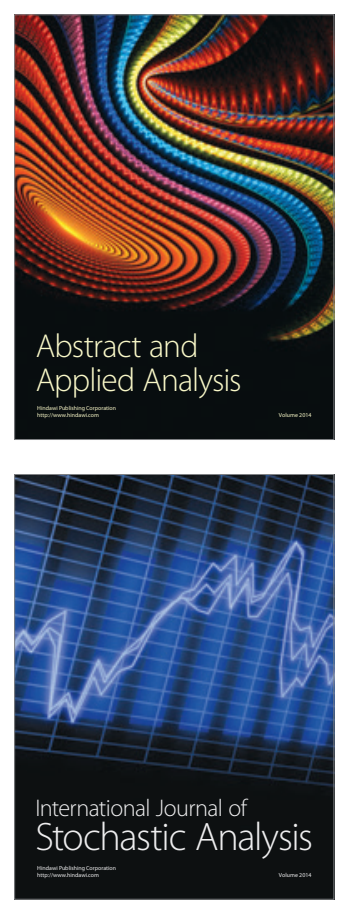

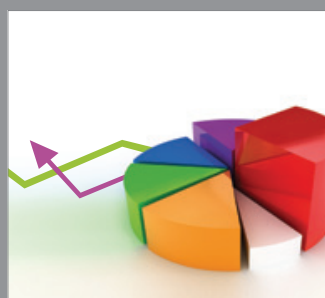

ournal of

Probability and Statistics

Promensencen
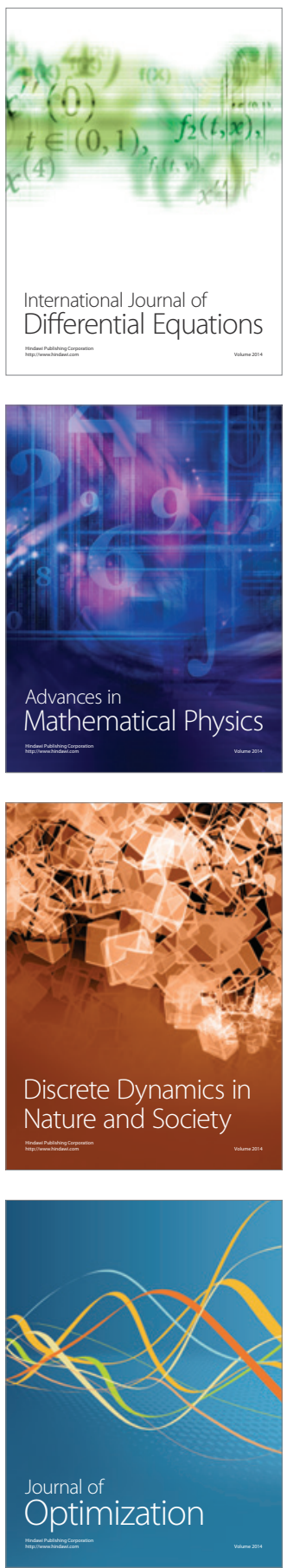